\title{
Clinical Responses to Intramammary Endotoxin Infusion in Dairy Cows Subjected to Feed Restriction ${ }^{1}$
}

\author{
K. H. Perkins, ${ }^{\star}$ M. J. VandeHaar, ${ }^{\star}$ J. L. Burton, ${ }^{\star}$ \\ J. S. Liesman, ${ }^{\star}$ R. J. Erskine,† and T. H. Elsasserł \\ *Department of Animal Science and \\ †Department of Large Animal Clinical Sciences, \\ Michigan State University, East Lansing 48824; and \\ ‡Growth Biology Laboratory, \\ USDA-ARS, BARC-East, Beltsville, MD.
}

\begin{abstract}
Nonpregnant, midlactation primiparous Holstein cows were fed ad libitum $(\mathrm{n}=12)$ or at $80 \%$ of maintenance energy requirements $(n=12)$ to determine whether feed restriction influences clinical response to endotoxin-induced mastitis. After 2 wk of ad libitum or restricted feeding, one mammary quarter per cow was infused with $100 \mu \mathrm{g}$ of endotoxin. Within 3 to $6 \mathrm{~h}$ of intramammary infusion, endotoxin increased mean rectal temperature, heart rate, and milk somatic cell count and immunoglobulin (IgG) concentration; and decreased blood leukocyte count and rumen motility in both restricted and ad libitum-fed cows. Mean serum and milk tumor necrosis factor-alpha (TNF- $\alpha$ ) concentrations showed only modest increases following endotoxin infusion. Restricted fed cows had slightly different acute fever responses and significantly increased heart and respiration rates than ad libitum fed cows. However, feed restriction did not influence mean total leukocyte count, rumen motility, serum TNF- $\alpha$ concentrations or milk IgG and TNF- $\alpha$ concentrations. Thus, results of this study suggest that energy balance does not significantly alter clinical symptoms following acute endotoxin-induced mastitis, at least in midlactation cows. As such, negative energy balance may not underlie the increases in severe coliform mastitis commonly observed in periparturient dairy cows.
\end{abstract}

(Key words: energy balance, mastitis, acute phase response, dairy cow)

Abbreviation key: EB = energy balance; LPS = lipopolysaccharide; $\mathbf{N E B}$ = negative energy balance; PEB

\footnotetext{
Received April 17, 2001.

Accepted August 5, 2001.

Corresponding author: M. J. VandeHaar; e-mail: mikevh@pilot. msu.edu.

${ }^{1}$ Supported by the Michigan Agricultural Experiment Station, USDA Animal Health Formula Funds, and the Michigan Animal Initiative Coalition.
}

$=$ positive energy balance; $\mathbf{T N F}-\alpha=$ tumor necrosis fac-
tor-alpha.

\section{INTRODUCTION}

In dairy cows, bacterial invasion and growth in the udder is most often the cause of mammary inflammation, or mastitis. Intramammary infusion of endotoxin can be used as a noninfectious provocative tool to study the inflammatory response in coliform mastitis because many of the clinical signs of intramammary coliform infections arise from the release of endotoxin from the infecting microbes (Jain et al., 1978; Hill et al., 1981; Guidry et al., 1983; Erskine et al., 1989). These clinical signs include increases in body temperature, heart, and respiration rates and reductions in rumen motility, appetite, and milk yield (Lohuis et al., 1988; Eades, 1993). Therefore, clinical coliform mastitis and endotoxin-induced mastitis are as much systemic diseases as they are inflammations of the mammary gland.

Several factors influence the duration and severity of systemic disease caused by IMI. These include the causative pathogen, stage of lactation, age, immune status of the cow, genetics, and nutritional status (Harmon, 1994). Nutritional status may be of particular importance in dairy cows around the time of parturition (Burvenich et al., 1999). Periparturient dairy cows experience multiple changes in physiology and metabolism associated with expulsion of the fetus and lactogenesis. The tremendous increase in energy demand for these processes, in combination with a steady decline in daily feed intake, induces moderate to severe negative energy balance (NEB) in most periparturient dairy cows. Noteworthy, however, is the significant increase in the incidence of severe coliform mastitis at this time. Therefore, a causal link between energy partitioning among tissues and physiological processes, energy intake, and altered disease susceptibility around parturition is likely more than coincidence.

In a previous study, we showed that dietary-induced NEB did not significantly influence general immune 
status in otherwise healthy dairy cattle (Perkins et al., 2001). However, Holstein steers were used as the animal model in those studies, and no attempt was made to determine the relevance of imposed NEB to clinical inflammatory diseases in those steers. The objective of the present study was to determine if NEB impacts the acute clinical response to endotoxin-induced mastitis in dairy cows. Nonpregnant, midlactation primiparous Holstein cows fed either ad libitum or at $80 \%$ of maintenance requirements and challenged intramammarily with endotoxin were used for this purpose.

\section{MATERIALS AND METHODS}

\section{Animals and Diets}

Twenty-four nonpregnant, primiparous Holstein cows between 77 and 118 DIM were used as the experimental animals. To be eligible for use in the study, each cow had to exhibit positive energy balance for $>2$ consecutive weeks and no signs of clinical mastitis or other diseases. Once these facts were established, cows were blocked into groups of two or four based on calving date and availability. Cows within a block were randomly assigned to receive one of two dietary treatments, a positive energy balance diet $(\mathbf{P E B} ; \mathrm{n}=12)$ or a NEB; $(\mathrm{n}=12)$. Both groups were fed a TMR balanced for 40 $\mathrm{kg}$ of daily milk production. On a DM basis, the diet contained $35 \%$ corn silage, $14 \%$ alfalfa, $14 \%$ corn grain, $6 \%$ cottonseeds, $7 \%$ corn distillers grains, $17 \%$ protein supplements, and $7 \%$ mineral/vitamin supplement. The diet was $32 \% \mathrm{NDF}$ and $19 \% \mathrm{CP}$. The calculated energy density was $1.74 \mathrm{Mcal}$ of $\mathrm{NE}_{\mathrm{L}} / \mathrm{kg}$, and $35 \%$ of the $\mathrm{CP}$ was estimated to be undegraded in the rumen. All minerals were fed to meet or exceed requirements of cows fed ad libitum, and trace minerals and vitamins $\mathrm{A}, \mathrm{D}$, and $\mathrm{E}$ were fed to meet requirements of NEB cows (NRC, 1989). The diet was formulated to contain Se at 0.43 $\mathrm{mg} / \mathrm{kg}$ and vitamin $\mathrm{E}$ at $10 \mathrm{IU} / \mathrm{kg}$. However, the PEB group was fed ad libitum, while the NEB group was fed at a restricted level to $\sim 80 \%$ of energy requirements for maintenance and milk production. Cows were fed their respective treatment diets for $14 \mathrm{~d}$ before intramammary endotoxin challenge. Calculated energy balance was monitored throughout this 14 -d period so the amount of feed offered to the NEB cows could be adjusted twice weekly to maintain feed energy intake at $80 \%$ of requirements as milk yield decreased. All cows were implanted with $6 \mathrm{mg}$ of norgestomet (SynchroMate B, Sanofi Animal Health, Overland Park, KS) on $\mathrm{d} 9$ of this dietary treatment period to ensure that animals had similar profiles of ovarian hormones during subsequent intramammary endotoxin challenges. Dietary treatments were continued through an addi- tional $2 \mathrm{~d}$ after endotoxin challenge, after which the study was concluded.

Energy requirement for maintenance was calculated $(\mathrm{NRC}, 1989)$, where requirement $=\left[\right.$ body weight $\left.(\mathrm{kg})^{0.75}\right]$ $\times[0.08 \mathrm{Mcal} / \mathrm{kg}]$. Energy in milk was determined as in Tyrrell and Reid (1965), where milk energy output $(\mathrm{Mcal} /$ day $)=[$ milk weight $(\mathrm{lb})] \times[41.63 \times(\%$ fat $)+24.13$ $\times(\%$ protein $)+21.6 \times(\%$ lactose $)-11.72] / 1000$. The total energy requirement was then calculated as [energy for maintenance + milk energy output]. Calculated energy balance $(\mathbf{E B})=\left[\mathrm{NE}_{\mathrm{L}}\right.$ consumed in feed $]-\left[\mathrm{NE}_{\mathrm{L}}\right.$ requirement for maintenance and milk]. If $\mathrm{EB}<0$, then $\mathrm{EB}=$ $\mathrm{EB} / 0.82$ to account for inefficiencies of using body tissues to meet metabolic energy needs. To make these various calculations, feed intake and milk yield were measured daily; concentrations of milk fat, protein, lactose, and SCC were determined 3 times per week by Michigan DHIA (East Lansing, MI) with a Bentley 2000 (Bentley Instrument, Chaska, MN); cows were weighed on 2 consecutive days per week, and DM content of the diet 2 times per week.

\section{Indicators of Energy Balance}

Several indicators of EB were monitored during the 14-d dietary treatment period to insure that PEB was maintained in the ad libitum fed cows and that NEB was established in the feed-restricted cows. Energy balance indicators included DMI (kg/d), 3.5\% FCM yield $(\mathrm{kg} / \mathrm{d})$, biweekly serum NEFA concentration $(\mu \mathrm{Eq} / \mathrm{L})$, and calculated energy balance ( $\mathrm{Mcal} / \mathrm{d}$; see above). Before feeding, blood for serum NEFA analysis was collected via tail venipuncture into $10-\mathrm{ml}$ Vacutainer tubes containing no anticoagulant $14,11,7,4$, and $0.5 \mathrm{~d}$ before endotoxin infusion, as well as immediately before endotoxin infusions. Blood was allowed to clot overnight at $4^{\circ} \mathrm{C}$, serum was harvested following centrifugation of the blood tubes $\left(1550 \times g\right.$ for $25 \mathrm{~min}$ at $\left.4^{\circ} \mathrm{C}\right)$, and samples were stored at $-20^{\circ} \mathrm{C}$ until assayed. Serum NEFA concentrations were determined enzymatically (NEFA-C Kit; Wako Pure Chemicals, Inc., Osaka, Japan) with an assay adapted for microtiter plates (Johnson and Peters, 1993).

\section{Intramammary Endotoxin Challenge}

Milk samples from each quarter of all cows were aseptically collected $12 \mathrm{~h}$ before endotoxin infusions and cultured on sheep blood agar plates to ensure that single quarters selected for endotoxin challenge were not infected with common mastitis-causing pathogens. Endotoxin was prepared by vortexing $100 \mu \mathrm{g}$ of Escherichia coli O111:B4 lipopolysaccharide (LPS; Sigma Chemical Co., St. Louis, MO) in $5 \mathrm{ml}$ of pyrogen-free 
(a)

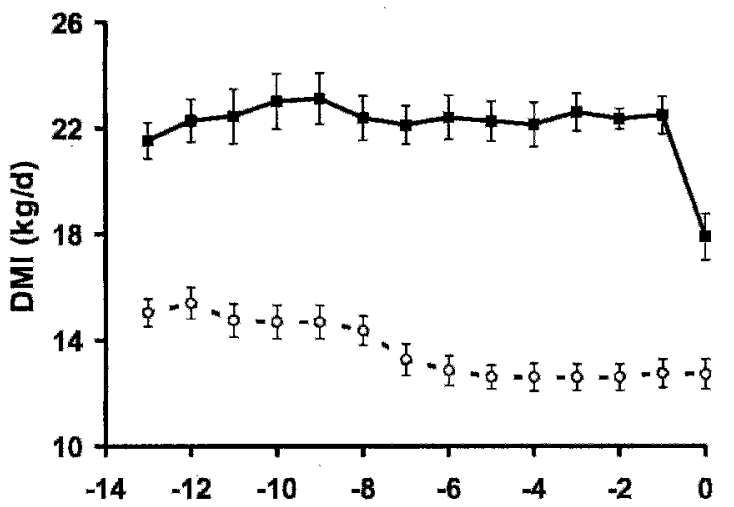

(c)

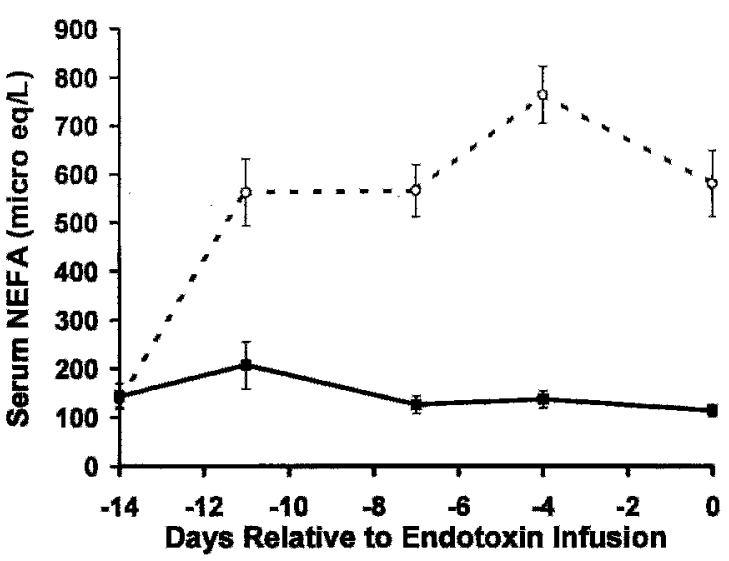

(b)

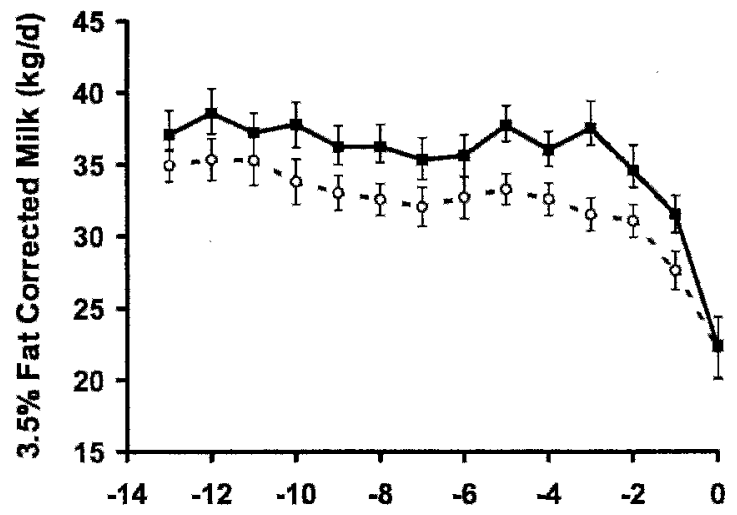

(d)

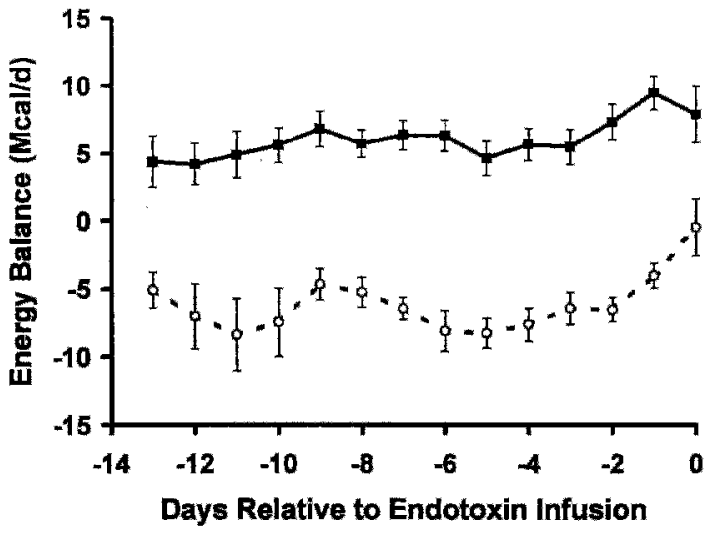

Figure 1. Daily means and SEM for DMI (a), 3.5\% milk FCM production (b), serum NEFA concentration (c), and calculated energy

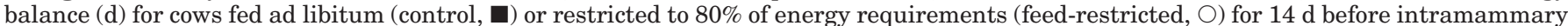
endotoxin infusions (on $\mathrm{d}$ ). All cows were in positive energy balance up to $\mathrm{d}-13$, at which time dietary treatments were commenced. The restriction fed cows were in clear negative energy balance when endotoxin was administered on $\mathrm{d} 0$.

physiological saline solution, for a final concentration of $20 \mu \mathrm{g} / \mathrm{ml}$. The suspension was stored at $4^{\circ} \mathrm{C}$ and mixed well before infusion. On the day of challenge, cows were milked at $0600 \mathrm{~h}$ and the entire $100-\mu \mathrm{g}$ LPS preparation infused intracisternally into one quarter per cow immediately after milking using sterile 5-cc syringes and $35-\mathrm{mm}$ disposable teat infusion cannula. Approximately one-third of the length of the cannula was placed (aseptically) into the teat. Following infusion of the LPS, teats and glands were massaged for 15 to $20 \mathrm{~s}$ to facilitate distribution of endotoxin into the infused quarters. Cows were milked out completely at 10 - to 12 -h intervals beginning $12 \mathrm{~h}$ before infusion and continuing until $48 \mathrm{~h}$ after infusion, using a portable automatic milker.

\section{Indicators of Clinical Disease}

A variety of systemic and local inflammatory indicators were used to monitor the clinical response to intra- mammary endotoxin challenge. Monitoring was initiated at $12 \mathrm{~h}$ before infusion (to establish baseline values), and then intensively at $0,2,3,4,6,9,12,24$, and $36 \mathrm{~h}$ postendotoxin infusion. Systemic indicators included fever $\left({ }^{\circ} \mathrm{C}\right.$; determined by rectal temperature); heart rate (beats/min), respiration rate (breaths/min), and rumen contraction rate (contractions/min), each determined by auscultation; total leukocyte count (millions of cells/L of blood) was determined by electronic cell counting [Coulter Particle Counter (Beckman Coulter, Fullerton, CA)]; and serum tumor necrosis factor-alpha (TNF- $\alpha$ ) concentration (ng/ml; determined by radioimmunoassay as in Kahl et al., 1997). Acute changes in milk concentrations of serum proteins, such as IgG, have been used as indicators of capillary permeability that accompanies the local inflammatory response in the mammary gland (Schalm, 1977; Guidry et al., 1983). Therefore, we also monitored milk IgG from the mammary quarter infused $(\mathrm{mg} / \mathrm{dl}$; determined 
by radial immunodiffusion using a RID kit from VMRD, Pullman, WA) at $0,3,6,9,12$, and $24 \mathrm{~h}$ postinfusion. Milk TNF- $\alpha$ concentrations (ng/ml; determined by radioimmunoassay as in Kahl et al., 1997) were monitored in a subset of samples ( 0,3 , and $6 \mathrm{~h}$ postinfusion). Milk samples for the IgG and TNF- $\alpha$ assays were processed into whey (Harmon, 1994) and the samples were stored at $-20^{\circ} \mathrm{C}$ until assays were performed at the end of the animal work. Also within $24 \mathrm{~h}$ of endotoxin infusion, milk samples from the quarter infused were analyzed for SCC (Michigan DHIA, East Lansing) using a Somacount 500 (Bentley Instrument). Maximum sensitivity for the Somacount 500 is 9.999 million cells per milliliter. Somatic cell counts for 11 samples were greater than the maximum sensitivity and were deleted before statistical analysis of this dataset. Somatic cell counts were determined in milk from all quarters before infusion and at $36 \mathrm{~h}$ and $1 \mathrm{wk}$ postinfusion.

\section{Statistical Analyses}

The various datasets of this study were analyzed using repeated measures analysis (SAS PROC MIXED, SAS Institute Inc., Cary, NC) modeling correlated residuals within cow (Littell et al., 1996). Erratic heterogeneous variance was observed on initial examination of empirical distributions of residuals for each dataset, so all datasets were ln-transformed before statistical analyses. This transformation resolved the unequal variance distributions in each dataset. The linear models used to statistically analyze the transformed data included fixed effects of treatment (PEB or NEB), time (relative to start of dietary treatment or relative to endotoxin infusion), and the treatment by time interaction. Models also included a random block effect and error term. Covariance between residuals within cow was modeled either as compound symmetry or as heterogeneous compound symmetry (Littell et al., 1996). Analyses relative to endotoxin infusion used observations from the first $24 \mathrm{~h}$ after infusion with first observation made before infusion as a covariate. Significant differences were declared when $P \leq 0.05$. Trends toward significance were declared when $P \leq 0.10$.

\section{RESULTS}

\section{Indicators of Energy Balance}

Four indicators of EB were used in this study to insure that cows fed ad libitum maintained PEB and those restricted to $80 \%$ of maintenance requirements achieved NEB. Data presented in Figure 1 summarize results of these dietary treatments on EB over the 14 $\mathrm{d}$ prior to endotoxin challenge. Figure 1a shows that the NEB group consumed approximately $40 \%$ less feed per day than the PEB group $(P<0.0001)$. This resulted in decreased FCM production for the NEB group that was $\sim 10 \%$ below that of PEB cows $(P<0.0001$; Figure 1b). Also, serum NEFA concentrations rose dramatically to $>500 \mu \mathrm{Eq} / \mathrm{L}$ by d 7 in the NEB group, compared with the maintained concentration of $\sim 105 \mu \mathrm{Eq} / \mathrm{L}$ in the PEB group $(P<0.0001$; Figure 1c). Finally, mean calculated EB in the NEB group dropped to approximately $-6.2 \pm 1.1 \mathrm{Mcal} / \mathrm{d}$, a value that was significantly lower $(P<0.0001)$ than the mean EB of PEB cows $(5.8 \pm 1.1 \mathrm{Mcal} / \mathrm{d}$; Figure 1d). These four EB indicators demonstrated our success in inducing and maintaining chronic NEB by restriction feeding. Similarly, these indicators showed that ad libitum feeding was successful in maintaining PEB in the control group of cows.

\section{Mean Clinical Response to Intramammary Endotoxin Infusion}

We intensively monitored a variety of systemic and local inflammatory indicators following intramammary infusion of endotoxin into one mammary quarter per cow. Endotoxin infusion caused acute (within 6 h) fever and increases in heart and respiration rates $(P<0.0001$; Figure 2). Each of these clinical indicators of the systemic inflammatory response to endotoxin returned to baseline values by $24 \mathrm{~h}$ postinfusion. As expected (Jain et al., 1978; Guidry et al., 1983; Kahl et al., 1997), endotoxin infusion also acutely reduced $(\sim 60 \%)$ mean blood leukocyte counts (Figure 3 ) and increased milk SCC $(P<0.0001$; Figure 4$)$ and IgG concentration $(P<$ 0.0001; Figure 5), and caused modest elevations in milk TNF- $\alpha$ concentrations $(P<0.0001$; Figure $6 \mathrm{~b})$ that were not so pronounced in serum (Figure 6a). Mean blood leukocyte counts and milk IgG concentrations returned to baseline levels by 24 and $36 \mathrm{~h}$, postinfusion, respectively, but milk SCC was still elevated $36 \mathrm{~h}$ after infusion. Milk SCC returned to baseline within $1 \mathrm{wk}$ of infusion. TNF- $\alpha$ concentrations in blood and milk stayed modestly elevated over the $6 \mathrm{~h}$ postinfusion period for which they were monitored. In combination with the indicators of EB in Figure 1, the mean clinical response to intramammary endotoxin infusion was repeatable enough to achieve the main objective of the study, which was to determine whether NEB impacts the acute clinical response to endotoxin-induced mastitis in dairy cows.

\section{Effects of Energy Balance on the Clinical Response to Endotoxin Infusion}

The effects of dietary treatment and treatment $\times$ time interaction were tested for each indicator of clinical 
(a)

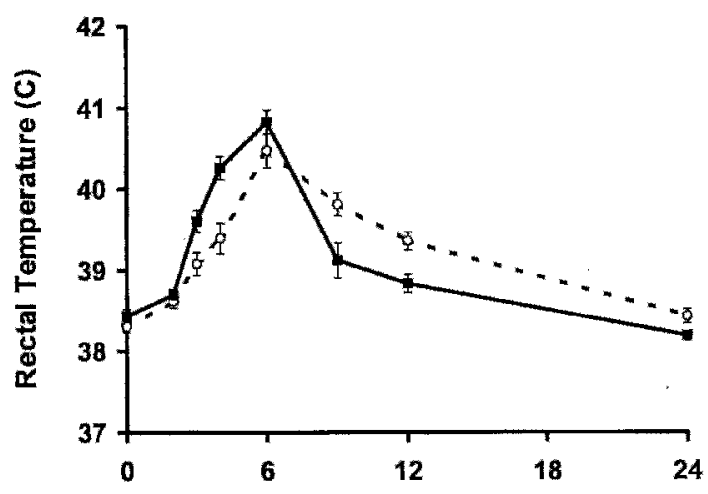

(c)

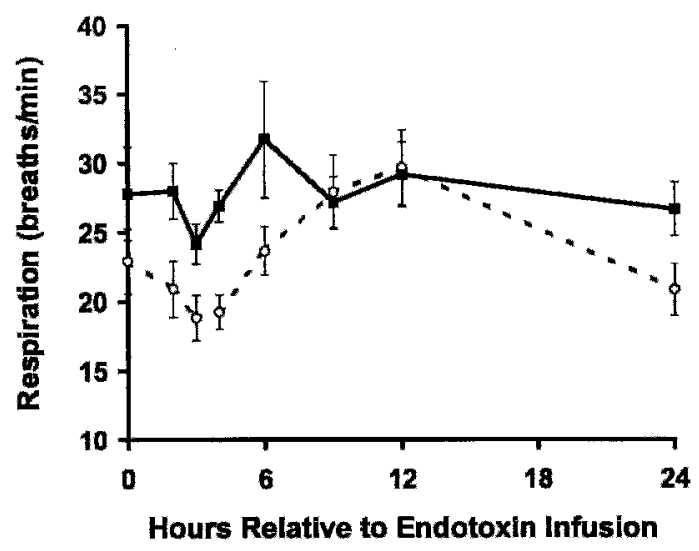

(b)

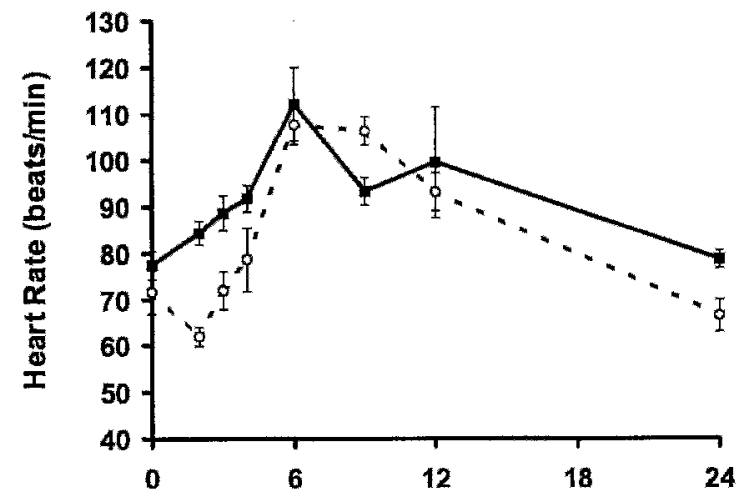

(d)

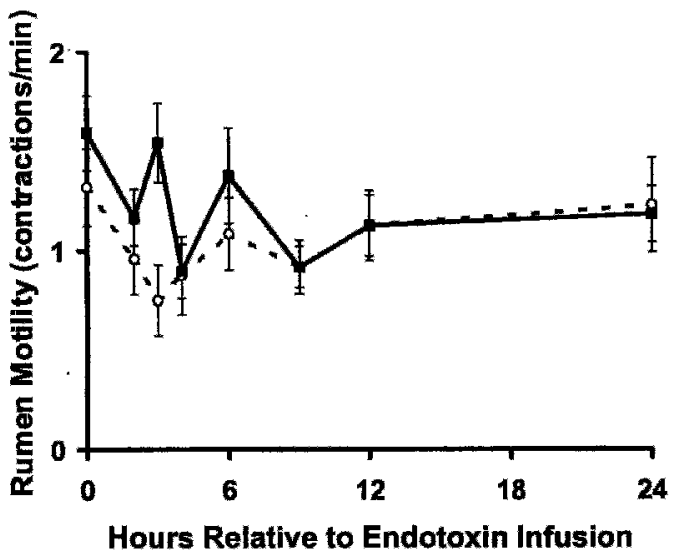

Figure 2. Hourly means and SEM for rectal temperature (a), heart rate (b), respiration rate (c), and rumen contraction rate (d) following intramammary infusion of endotoxin in cows fed ad libitum (control, $\mathbf{\square}$ ) or restricted to $80 \%$ of maintenance requirements (feed-restricted, $\bigcirc$ ).

response to endotoxin infusion. First, there was a significant treatment $\times$ time interaction for the fever response to endotoxin infusion $(P<0.0001$; Figure 2a). NEB cows had lower rectal temperatures 3 and $4 \mathrm{~h}$ postendotoxin infusion than did PEB cows $(P<0.05)$ and maintained higher rectal temperatures between 9 and $12 \mathrm{~h}$ postinfusion $(P<0.05)$. However, peak fever response $\left(\sim 40.8^{\circ} \mathrm{C}\right.$ at $\left.6 \mathrm{~h}\right)$ and time to full recovery from fever (at $24 \mathrm{~h}$ ) were not influenced by NEB.

Negative energy balance influenced the tachycardia response following intramammary infusion of endotoxin in a similar manner as the fever response with a significant treatment by time interaction $(P<0.0001)$. For example, NEB cows exhibited slower heart rates than PEB cows 2,3 , and $4 \mathrm{~h}$ postendotoxin infusion $(P$ $<0.05$ ) but had higher heart rates $9 \mathrm{~h}$ postendotoxin $(P<0.05$; Figure $2 \mathrm{~b})$. Peak heart rate response $(\sim 110$ beats/min at $6 \mathrm{~h}$ ) and time to full recovery of heart rate (at $24 \mathrm{~h}$ ) were not influenced by NEB (Figure $2 \mathrm{~b}$ ).
Mean respiration rate was generally lower in NEB cows than PEB cows, even before the infusion of endotoxin $(P<0.01$; Figure $2 \mathrm{c})$, likely as a result of reduced DMI (Figure 1a) and milk yield (Figure 1b). Mean respiration rates began to rise $\sim 4 \mathrm{~h}$ postendotoxin infusion. In the PEB cows, this response was modest at best, peaking at $6 \mathrm{~h}$ postinfusion $(\sim 20 \%$ higher than at 3 h) and returning to normal by $9 \mathrm{~h}$. However, mean respiration rates in the NEB cows continued to increase between 4 and $12 \mathrm{~h}$ postendotoxin infusion, reaching a peak 12 -h rate that was almost $40 \%$ greater than the 3 -h rate (Figure 2c). Respiration rate for NEB cows returned to preendotoxin infusion rates by $24 \mathrm{~h}$ postinfusion. Data in Figure 2c thus suggest that the respiratory response to intramammary endotoxin may be slightly more intense and prolonged when cows are in NEB than when they are in PEB.

The acute response of the rumen to endotoxin infusion was not affected by EB, both dietary treatment 


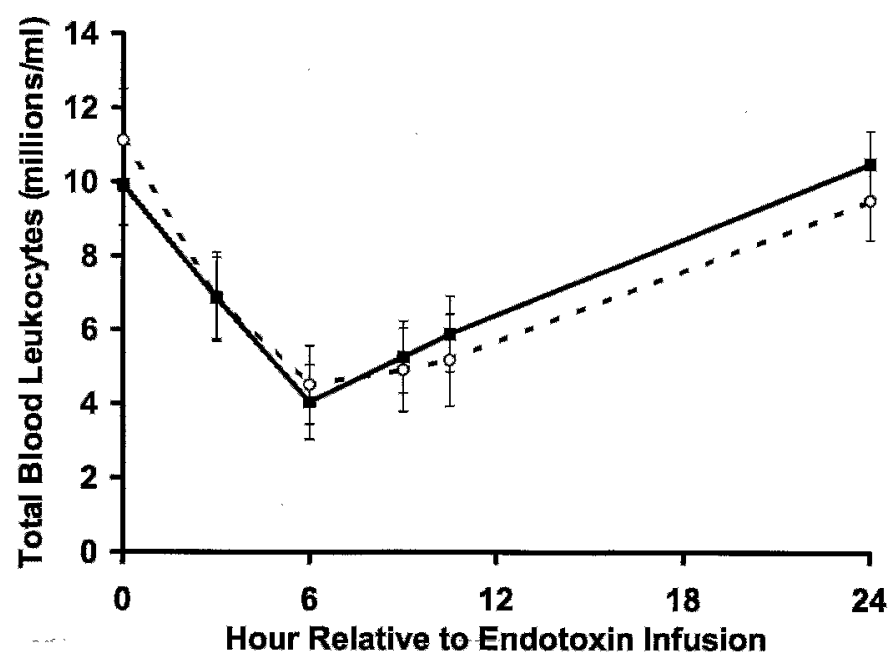

Figure 3. Hourly means and SEM for number of blood total leukocytes following intramammary infusion of endotoxin in cows fed ad libitum (control, - ) or restricted to $80 \%$ of maintenance requirements (feed-restricted, $\bigcirc$ ).

groups exhibiting similar decreases in rumen motility between 2 and $24 \mathrm{~h}$ postinfusion (Figure $2 \mathrm{~d}$ ). Also, EB did not influence total blood leukocyte (Figure $3 ; P>$ 0.10 ), milk IgG (Figure 5; $P>0.10$ ), or serum and milk TNF- $\alpha$ (Figure $6 ; P>0.10$ ) responses to intramammary endotoxin infusion.

\section{DISCUSSION}

As evidenced by daily DMI, milk yield, calculated energy balance, and biweekly serum NEFA concentra-

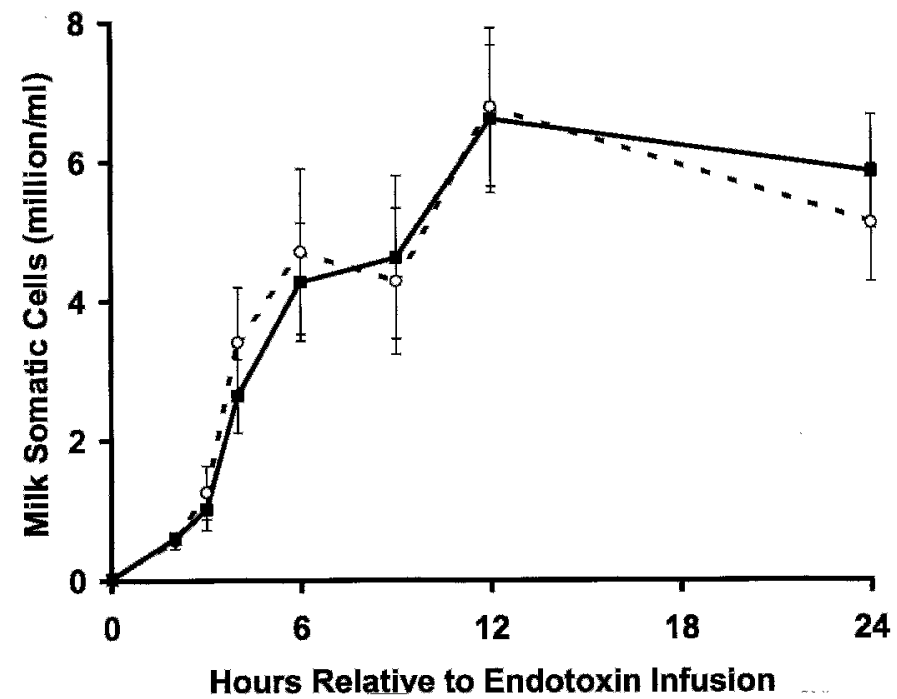

Figure 4. Hourly means and SEM for milk SCC from the quarter infused following intramammary infusion of endotoxin in cows fed ad libitum (Control, ) or restricted to $80 \%$ of maintenance requirements (feed-restricted, $\bigcirc$ ).

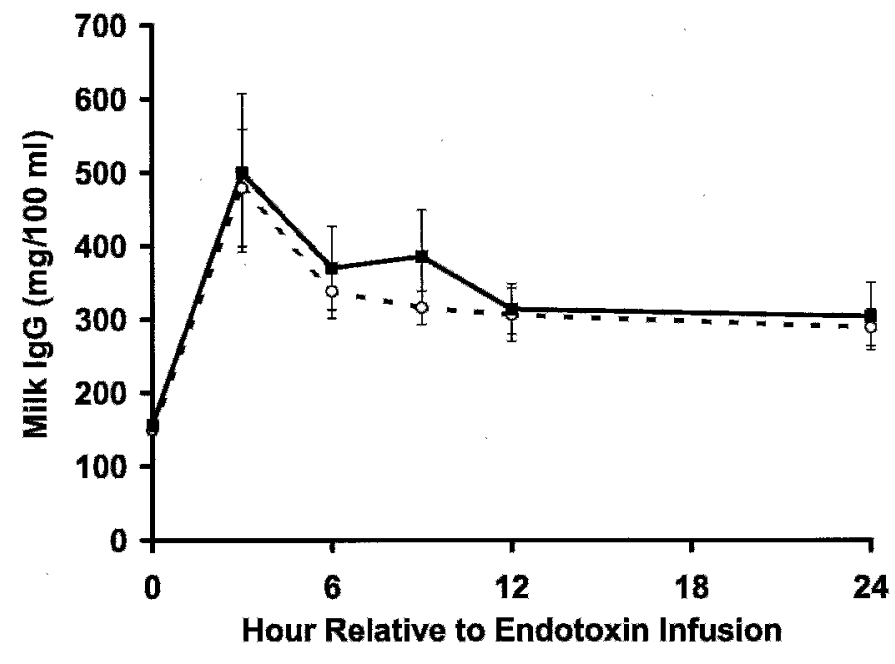

Figure 5. Hourly means and SEM for milk IgG concentration following intramammary infusion of endotoxin in cows fed ad libitum (control, - or restricted to $80 \%$ of maintenance requirements (feedrestricted, $\bigcirc$ ).

tions (Figure 1), feed restriction caused acute and sustained NEB in the lactating dairy cows of this study. Our intramammary endotoxin infusions caused the expected clinical signs of systemic and local disease, evidenced by fever response, increased respiration and heart rates, decreased rumen motility (Figure 2) and blood leukocyte counts (Figure 3), slightly increased serum TNF- $\alpha$ concentrations (Figure 6a), and more pronounced increases in milk SCC (Figure 4), IgG (Figure 5 ) and TNF- $\alpha$ concentrations (Figure 6b).

The main question addressed by this study was whether dietary-imposed NEB alters responsiveness of lactating dairy cows to intramammary endotoxin challenge. The only notable effects of imposed dietary energy deficiency in this study were on fever, tachycardia, and respiration rates, which were slightly lower in NEB cows than PEB cows up to $6 \mathrm{~h}$ postendotoxin infusion (Figure 2). Fever and tachycardia are caused by interactions between various cytokine networks and the neuroendocrine system (reviewed in Elsasser et al., 2000; Kelley, 1988). Although NEB had minimal effects on blood and milk TNF- $\alpha$ concentrations in this study (Figure 6), it is possible that nutrient deficit altered the sensitivity of cytokine-neuroendocrine networks in the feed restricted cows (Elsasser et al., 2000). In support of this possibility, Shuster et al. (1996) reported that early-lactation dairy cows (probably in NEB) with coliform mastitis had significantly higher rectal temperatures than mastitic midlactation cows (probably in PEB), as well as significantly higher TNF and interleukin-8 responses. Therefore, it is possible that the differences in cytokine, fever, and tachycardia responses ob- 
(a)

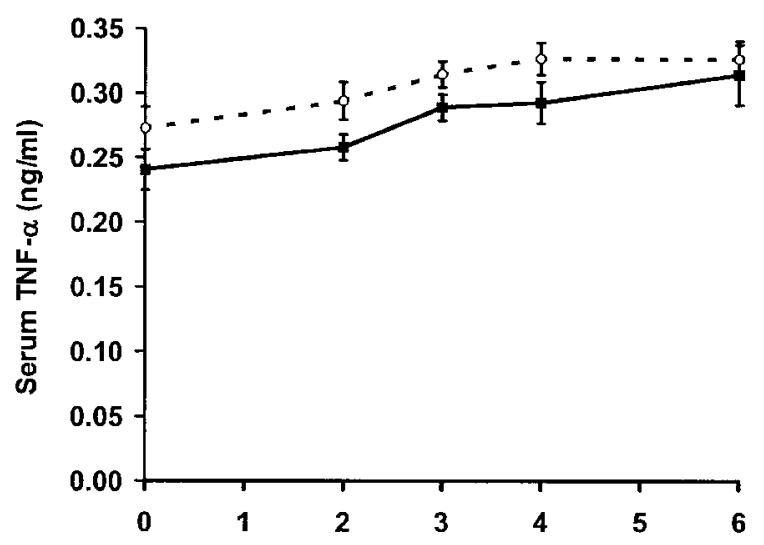

(b)

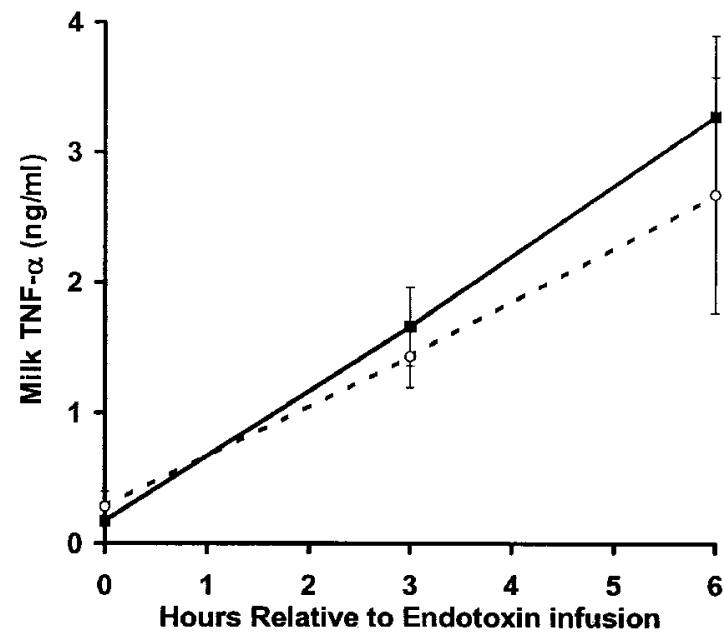

Figure 6. Hourly means and SEM for tumor necrosis factor-alpha (TNF- $\alpha$ ) concentrations in serum (a) and milk (b) following intramammary infusion of endotoxin in cows fed ad libitum (control, $\mathbf{0}$ ) or restricted to $80 \%$ of maintenance requirements (feed-restricted, $\bigcirc$ ).

served by Shuster et al. (1996) were related to energy balance. It might be interesting to substantiate this possibility through more holistic experiments designed to explore multiple cytokine-neuroendocrine gene expression cascades in relevant tissues of endotoxin-challenged cows with imposed NEB versus PEB. That said, whole animal clinical responses such as peak fever and tachycardia and return of these to baseline were not influenced by EB in the present study. Therefore, it appears that the impact of NEB on acute clinical responses during experimental endotoxin-induced mastitis is minimal. This was further supported by our data showing no effects of NEB on total blood leukocyte counts, serum TNF- $\alpha$ concentrations, or milk SCC, TNF- $\alpha$, and IgG concentrations. However, these rather gross indicators of response to experimentally induced endotoxin mastitis may not tell the full story about potential roles for NEB in more subtle modulation of potent cytokine-neuroendocrine networks (Elsasser et al., 2000), or about possible influences of nutrient deficiency on the severity of acute mastitis from natural coliform infections.

Certainly, other studies have been published that support the notion of altered immune function in cattle during nutrient deficiency. For example, surgical removal of the mammary gland before calving to remove the demands for energy at the onset of lactation accelerates recovery of circulating leukocyte numbers after calving (Kimura et al., 1999). In addition, deficiencies in specific nutrients such as selenium and vitamin $\mathrm{E}$ that accompany NEB often result in increased incidence and severity of mastitis, while supplementation of diets with Se and vitamin E significantly reduces frequency and duration of clinical mastitis (Smith et al., 1984; Erskine et al., 1989). The NEB cows of the present study were feed-restricted and thus may have had concurrent deficiencies in some or all vitamins and minerals, as well as in protein. It is possible that these single-nutrient deficiencies played a role in altering the fever and tachycardia responses to intramammary endotoxin infusion in the current group of cows, perhaps through effects on the cytokine-neuroendocrine axis. Indeed, other researchers have shown that the nutritional influence on cytokine responses to endotoxin is an intricate interplay between protein and energy status, lowprotein diets resulting in a TNF- $\alpha$ response to endotoxin greater in magnitude than high-protein diets (Kahl et al., 1997; Elsasser et al., 2000). Where periparturient cows are concerned, NEB and accompanying single nutrient deficiencies may be quite different than in midlactation cows because immunosuppression exists as a separate but interconnected contributor to altered mammary inflammatory responses around parturition. Therefore, it would be interesting to repeat the current study on midlactation cows with imposed immunosuppression, to determine whether EB impacts clinical responses in this scenario. Furthermore, endotoxin, while a convenient inducer of mammary inflammation, is noninfectious and may be inappropriate for studies designed to assess host defenses related to acute coliform mastitis. Therefore, future NEB studies of this nature may benefit from using mastitis-causing coliforms to induce mammary inflammation.

In summary, results of the current study suggest that NEB has a minimal impact on acute clinical responses to intramammary endotoxin challenge. It is thus tempting to conclude that NEB is not an underlying susceptibility factor for severe coliform mastitis. However, additional NEB studies with immunosuppressed midlactation cows challenged intramammarily with mastitiscausing coliforms are required to substantiate this con- 
clusion and extend its implications to the early-lactation cow.

\section{ACKNOWLEDGMENTS}

The authors thank Robert Kreft, Jose Dykstra, John Whitmore, Tasha Lipinski, and Greg Baker and Jill Davidson for technical assistance.

\section{REFERENCES}

Burvenich, C., M. J. Paape, D. Hoeben, H. Dosogne, A. M. MassertLeen, and J. Blum. 1999. Modulation of the inflammatory reaction and neutrophil defense of the bovine lactating mammary gland by growth hormone. Domest. Anim. Endocrinol. 17:149-159.

Eades, S. C. 1993. Endotoxemia in dairy cattle: Role of eicosanoids in reticulorumen stasis. J. Dairy Sci. 76:414-420.

Elsasser, T. H., K. C. Klasing, N. Filipov, and F. Thompson. 2000. The metabolic consequences of stress: targets for stress and priorities of nutrient use. Pages 77-110 in CAB International 2000 The Biology of Animal Stress. G. P. M. Obergand and J. A. Mench, eds. CABI Publishing, New York.

Erskine, R. J., R. J. Eberhart, P. J. Grasso, and R. W. Scholz. 1989. Induction of Escherichia coli mastitis in cows fed selenium-deficient or selenium-supplemented diets. Am. J. Vet. Res. 50:2093-2100.

Guidry, A. J., M. Ost, I. H. Mather, W. E. Shainline, and B. T. Weinland. 1983. Sequential response of milk leukocytes, albumin, immunoglobulins, monovalent ions, citrate, and lactose in cows given infusions of Escherichia coli endotoxin into the mammary gland. Am. J. Vet. Res. 44:2262-2267.

Harmon, R. J. 1994. Physiology of mastitis and factors affecting somatic cell counts. J. Dairy Sci. 77:2103-2112.

Hill, A. W. 1981. Factors influencing the outcome of Escherichia coli mastitis in the dairy cow. Res. Vet. Sci. 31:107-112.

Jain, N. C., O. W. Schalm, and J. Lasmanis. 1978. Neutrophil kinetics in endotoxin-induced mastitis. Am. J. Vet. Res. 39:1662-1667.
Johnson, M. M., and J. P. Peters. 1993. An improved method to quantify nonesterified fatty acids in bovine plasma. J. Anim. Sci 71:753-756

Kahl, S., T. H. Elsasser, and J. W. Blum. 1997. Nutritional regulation of plasma tumor necrosis factor-alpha and plasma and urinary nitrite/nitrate responses to endotoxin in cattle. Proc. Soc. Exp. Biol. 215:370-376.

Kelley, K. W. 1988. Cross-talk between the immune and endocrine systems. J. Anim. Sci. 66:2095-2108.

Kimura, K., J. P. Goff, and M. E. Kehrli. 1999. Effects of the presence of the mammary gland on expression of neutrophil adhesion molecules and myeloperoxidase activity in periparturient dairy cows. J. Dairy Sci. 82:2385-2392.

Littell, R. C., G. A. Milliken, W. W. Stroup, and R. D. Wolfinger. 1996. SAS System for mixed models. SAS Institute Inc., Cary, NC. pp 87-114.

Lohuis, J. A. C. M., W. Van Leeuwen, J. H. M. Verheijen, A. S. J. P. A. M. Van Miert, and A. Brand. 1988. Effect of dexamethasone on experimental Escherichia coli mastitis in the cow. J. Dairy Sci. 71:2782-2789.

National Research Council. 1989. Nutritional Requirements of Dairy Cattle. 6th rev. ed. Natl. Acad. Sci., Washington, D.C.

Perkins, K. H., M. J. VandeHaar, R. J. Tempelman, and J. L. Burton. 2001. Negative energy balance does not decrease expression of leukocyte adhesion or antigen presenting molecules in cattle. J. Dairy Sci. 84:421-428.

Schalm, O. W. 1977. Pathologic changes in the milk and udder of cows with mastitis. JAVMA 170:1137-1140.

Shuster, D. E., E. K. Lee, and M. E. Kehrli. 1996. Bacterial growth, inflammatory cytokine production, and neutrophil recruitment during coliform mastitis in cows within ten days after calving, compared with cows at midlactation. Am. J. Vet. Res. 57:15691575.

Smith, K. L., J. H. Harrison, D. D. Hancock, D. A. Todhunter, and H. R. Conrad. 1984 Effect of vitamin E and selenium supplementation on incidence of clinical mastitis and duration of clinical symptoms. J. Dairy Sci. 67:1293.

Tyrrell, H. F., and J. T. Reid. 1965. Prediction of the energy values of cow's milk. J. Dairy Sci. 48:1215-1223. 